\title{
VARIÁVEIS DE CUSTOS DE PRODUÇÃO DA CANA-DE-AÇÚCAR E SUAS DIFERENÇAS ENTRE AS REGIÕES PRODUTORAS
}

\author{
Nevison Amorim Pereira
}

RESUMO: Diante da importância do agronegócio brasileiro para a economia nacional e do crescimento da produção no setor sucroenergético, a avaliação dos custos das regiões produtoras pode melhorar a alocação dos recursos produtivos. O objetivo deste trabalho foi identificar as diferenças dos custos de produção da cana-de-açúcar das regiões Nordeste, Centro-Sul tradicional e Centro-Sul expansão, no que diz respeito às safras 2007/2008 a 2011/2012 no Brasil. A pesquisa se caracterizou como descritiva, utilizando-se de procedimento técnico documental e abordagem quantitativa. Os testes estatísticos aplicados foram Tukey e KruskalWallis para identificar quais custos sofreram variações estatisticamente significativas entre as regiões. Os resultados mostram que o maior custo médio da atividade se refere à mecanização nas regiões Centro-Sul tradicional e Centro-Sul expansão, enquanto na região Nordeste se relaciona à mão de obra. Das variáveis analisadas apenas mecanização, arrendamento da terra e mão de obra apresentaram diferenças estatisticamente significativas.

PALAVRAS-CHAVE: Custos; Cana-de-açúcar; Brasil.

\section{COSTS VARIABLES IN SUGAR-CANE PRODUCTION AND DIFFERENCES BET WEEN PRODUCING REGIONS}

ABSTRACT: In the wake of the importance of Brazilian agribusiness for national economy and production growth within the sugarcane-fuel sector, costs assessment of producing areas may improve the establishment of production. Current analysis identifies the differences in production costs of sugarcane in the northeastern region of Brazil, the traditional center-south area and the center-south expansion area with regard to harvests between 2007/2008 and 2011/2012 in Brazil. Descriptive research employed documental and technical procedures and a quantitative approach. Tukey's and Kruskal-Wallis's statistical tests identified which costs had the highest statistically significant variations among the regions. Results show that highest mean cost implies mechanization in the traditional and expansion center-south region, whereas man power is proper to the northeastern region. Mechanization, land rent

Mestre em Ciências Contábeis pela Universidade Federal de Uberlândia (UFU), Brasil.

E-mail: nevisonpm@yahoo.com.br 
and man power revealed statistically significant differences of the variables under analysis.

KEY WORDS: Costs; Sugar-cane; Brazil.

\section{INTRODUÇÃO}

No agronegócio, a indústria brasileira da cana-de-açúcar tem papel de destaque na economia nacional, principalmente, pela produção de açúcar, etanol e energia. O Brasil é líder no complexo sucroenergético e maior produtor mundial de cana e açúcar. Nesse sentido, aproximadamente, 50\% da produção brasileira se transformam em etanol e 50\%, em açúcar, enquanto nos demais países produtores de cana (Austrália, Índia e outros) a totalidade é direcionada para a produção de açúcar (CARVALHO; OLIVEIRA, 2006).

No Brasil, a plantação de cana é feita principalmente nas regiões Nordeste (Estados de Pernambuco e Alagoas); Centro-Sul tradicional (São Paulo - exceto oeste, Paraná e Rio de Janeiro) e Centro-Sul expansão (Mato Grosso do Sul, Minas Gerais Triângulo Mineiro, Goiás e o oeste paulista). Destas regiões, a principal produtora é a Centro-Sul tradicional (63\%) seguida pela Centro-Sul expansão (27\%) e Nordeste (10\%) (MARQUES, 2009; CHADDAD, 2010; BRASIL, 2012).

Algumas razões para que a região Centro-Sul tradicional tenha destaque na produção é porque dispõe das melhores condições de capital, gestão e instituições de pesquisa (VIEIRA JÚNIOR et al., 2008). Todavia, a produtividade e a competitividade são distintas entre as regiões produtoras pelas tecnologias empregadas e pelas ações políticas implementadas pelo governo (MARTINS et al., 2007).

Algumas práticas são essenciais para a competitividade nas usinas canavieiras como, por exemplo, o aperfeiçoamento permanente das operações que reduz os custos e aumentam a produtividade (BRUNOZI JÚNIOR et al., 2012).

$\mathrm{O}$ incremento da produtividade ocorre de três maneiras principais: adoção de novas tecnologias e formas de gestão, diferenciação da qualidade do produto pela colheita e redução dos custos de produção (OLIVEIRA; NACHILUK, 2011).

O sucesso de qualquer empreendimento depende do controle e da 
capacidade de redução dos custos de produção e não apenas da produtividade (CARVALHO; FIÚZA; LOPES, 2008).

Os sistemas de produção da cana-de-açúcar, influenciados por questões legais, políticas e ambientais, têm apresentado diferenças tecnológicas nas regiões produtoras que acabam afetando os custos de produção. Essas diferenças, tanto no uso de novas variedades quanto na utilização da mecanização, provocam efeitos distintos na produção e na competição do setor (MARTINS et al., 2007).

Um dos fatores para redução dos custos unitários é o incremento da produção por economia de escala, inibindo a entrada de novos concorrentes no mercado (NICOLELI; MOLLER, 2006). O custo de produção, portanto, é um dos fatores que influenciam na competitividade, visto que as empresas não devem simplesmente repassar seus custos aos consumidores (KENNEDY; HARRISON; PIEDRA, 1998).

Os custos de produção são afetados por fatores como economia de escala, experiência na produção, aumento dos preços dos insumos, competitividade do mercado, pesquisa e desenvolvimento que induz mudanças tecnológicas (NUNEZ, 2013).

As mudanças tecnológicas na cultura da cana-de-açúcar visam minimizar o impacto ambiental, melhorar a qualidade da cana, aumentar a produtividade e diminuir custos de produção (SILVA, 2009). Nesse ponto, grande parte do incremento de produtos derivados da cana é decorrente, principalmente, dos avanços tecnológicos que aumentam a produtividade e diminuem custos (NEVES et al., 2011).

De forma a complementar à compreensão dos custos de produção, verificou-se que a indústria do açúcar e etanol tem enfrentado aumento nos custos de produção nas últimas safras. Os custos de produção da cana aumentaram em 71\% na região Centro-Sul tradicional e em 51\%, na Centro-Sul expansão entre as safras 2007/2008 e 2011/2012, sendo a principal razão para a variação nos preços dos fatores de produção. O aumento constante do preço do açúcar e etanol no período resultou num aumento de $186 \%$ no preço das terras na região tradicional e de $154 \%$ na região de expansão, tendo um impacto direto sobre o custo de produção e, em particular, sobre o arrendamento das terras (XAVIER, 2012).

Outros fatores que contribuíram para o aumento dos custos de produção, 
segundo Xavier (2012), foram a crise financeira que impactou o setor, a taxa de inflação brasileira de cerca de 30\% no período e a valorização do Real em torno de 15\% em relação ao Dólar. O autor argumenta que as diferenças regionais entre as práticas dos produtores também explicam diferenças nos custos de produção.

Nesse sentido, na safra de 2007/2008, os produtores da região CentroSul expansão tiveram custos $9 \%$ abaixo que a região Centro-Sul tradicional. Já na safra 2011/2012, a diferença aumentou para $20 \%$. O preço do aluguel da terra, a utilização mais eficiente do maquinário, a rotação adequada de culturas com a cana e a economia de escala explicam as razões pelo custo mais baixo na região expansão (XAVIER, 2012).

Por sua vez, os custos de produção da região Nordeste são mais elevados em comparação aos da região Centro-Sul por causa da baixa fertilidade dos solos, menor volume de chuvas e topografia inadequada para mecanização (KOHLHEPP, 2010).

A tendência de alta nos custos de produção ainda foi observada em 2013 por aumento de preços nos insumos, gastos com mão de obra, incorporação de tecnologia, e, principalmente, a mecanização e a seca na região Nordeste (REETZ et al., 2013).

De acordo com Xavier (2012), dois terços do custo do açúcar bruto é referente à produção da cana, sendo que 70\% são produzidos pela própria usina e o restante é fornecido por outros agricultores. Além disso, o uso da capacidade industrial tem sido baixo, resultando no aumento dos componentes de custos fixos como custo de capital e depreciação. Os principais fatores de custo de produção do etanol são os mesmos do açúcar, e a principal diferença é a maior estabilidade dos preços de mercado.

Com relação aos custos no mercado internacional, Baiyegunhi e Arnold (2011) afirmam que os produtores de cana da África do Sul têm sido incapazes de cobrir os custos de produção, apresentando aumento estimado de $45 \%$ entre as safras 2003/04 e 2007/08 em razão, principalmente, do aumento do preço dos combustíveis, fertilizantes e mão de obra, causando problemas de fluxo de caixa e solvência. Esse aumento tem impactado a estrutura, a performance e o crescimento $\mathrm{da}$ indústria. $\mathrm{O}$ estudo também indicou um retorno decrescente de escala e ineficiência na alocação dos recursos.

Contemporaneamente, a indústria da cana é um dos mais fortes setores 
do agronegócio brasileiro e está passando por mudanças significativas em suas operações, incluindo modificação nos procedimentos de plantio e colheita, crescimento na produção de bioenergia, implantação de novas tecnologias e novos produtos, tais como bioplásticos (VIANA; PEREZ, 2013).

Segundo dados da União da Indústria de Cana-de-Açúcar (UNICA, 2014), essa participação tem em seu conjunto a representatividade de uma indústria da cana brasileira composta por cerca de 70 mil produtores, 389 unidades de processamento (usinas e destilarias), 1,09 milhão de postos de trabalho formais, espalhando-se a produção por 8,8 milhões de hectares.

Devido à especificidade de ativos envolvidos na transação entre produtores de cana e as usinas, três tipos de acordos são utilizados pela indústria: i) Produção própria - as usinas possuem a terra para a plantação da cana; ii) Arrendamento as terras utilizadas para a produção são alugadas dos proprietários da terra; iii) Produção terceirizada - os agricultores fornecem a cana para a indústria por meio de contratos (VIANA; PEREZ, 2013).

Para Gonçalves (2009), o crescimento do setor, de modo geral, apresenta-se mais de forma extensiva (ocupação de novas áreas) que de forma intensiva (elevação da produtividade por hectare). Por sua vez, o crescimento da produtividade foi associado à melhoria de insumos, aos tratos culturais, às novas variedades e ao manejo, impondo a necessidade de melhorias (FREITAS; MENDONÇA, 2008). Por esse ângulo, conforme Neves e Trombin (2014), na última década, a produção aumentou $64 \%$ e a área produtiva expandiu em $84 \%$.

Dessa forma, frente à importância do setor sucroenergético e da gestão de custos, o objetivo desse trabalho foi identificar as diferenças dos custos de produção da cana-de-açúcar nas três regiões em estudo.

O estudo analisou as regióes Nordeste, Centro-Sul tradicional e Centro-Sul expansão com base nos custos de produção, pois ainda existem grandes diferenças estruturais, tecnológicas e agrícolas entre estas regiões (ALVES et al., 2008).

A justificativa para o estudo encontra respaldo, porque

Há pouca precisão nas informações sobre custos de produção dos produtos do setor sucroalcooleira, uma vez que são poucos os trabalhos públicos sobre o tema, além da falta de uma metodologia de aferição de custos comum às diversas unidades industriais (MARQUES, 2009, p.15). 
O enfoque do ponto de vista dos custos de produção é importante, pois, ao calcular o custo, o produtor tem condições de avaliar os resultados, corrigir falhas e melhorar a produtividade.

\section{MATERIAIS E MÉTODOS}

Conforme apresentado anteriormente, a plantação de cana-de-açúcar, no Brasil, é feita principalmente nas regiões Centro-Sul tradicional (São Paulo - exceto oeste, Paraná e Rio de Janeiro), Nordeste (Estados de Pernambuco e Alagoas); e Centro-Sul expansão (Mato Grosso do Sul, Minas Gerais - Triângulo Mineiro, Goiás e o oeste paulista). Por esse motivo, essas três regiões foram selecionadas para o estudo, tendo sido o processo de amostragem o não probabilístico, considerando que as regiões foram escolhidas pela disponibilidade e acessibilidade dos dados.

Os dados foram extraídos, da base eletrônica do Centro de Estudos Avançados em Economia Aplicada da Escola Superior de Agricultura Luiz de Queiroz/Universidade de São Paulo (Cepea - Esalq/USP) entre as safras 2007/2008 a 2011/2012. O período das safras se deve à disponibilidade dos dados. A utilização dos relatórios do Cepea ocorreu porque, a partir da tabulação dos dados, esses eram os elementos mais recentes dos custos de produção disponíveis referentes à cultura da cana-de-açúcar nas regiões, e o órgão é referência no estudo de custos de produção da cultura.

A coleta de dados ocorreu no período de fevereiro de 2014 a abril de 2014, no sítio do Cepea, tendo sido considerado os seguintes custos: mão de obra, mecanização, insumos, arrendamento, despesas administrativas, remuneração da terra e remuneração do capital.

A justificativa para escolha das variáveis se dá em razão da classificação dos custos feito pelo Cepea e da segunda pressuposição de homogeneidade citada por Dyson et al. (2001), em que recursos similares estão disponíveis para todas as unidades e podem ser apresentados em um denominador comum.

Para a análise descritiva dos dados, utilizou-se o software Action ${ }^{\circledR}$ (ESTATCAMP, 2014), com a finalidade de avaliar os valores máximos, mínimos, médias, desvio-padrão, coeficiente de variação e testes de comparações. 
Visando complementar a análise com intenção de identificar quais custos sofreram variações estatisticamente significativas entre as regiões, foi realizada a análise de variância (ANOVA). A principal pressuposição da Anova é que os resíduos tenham distribuição normal. Assim, para verificar a normalidade dos resíduos, foi realizado o teste de Anderson-Darling, sendo considerado estatisticamente significativo o p-valor abaixo do valor nominal de significância de 5\%.

Em seguida, para as variáveis que apresentaram distribuição normal, foi utilizado o teste de Tukey que, segundo Arango (2001), é empregado para determinar se há diferenças significantes entre as médias dos grupos analisados no teste da análise de variância (Anova), tomadas duas a duas.

O teste de Tukey tem como base a diferença mínima significativa (DMS), representada no geral por $\Delta$ e calculada da seguinte forma:

$$
\Delta(\alpha)=q a \sqrt{Q M \operatorname{Re} \frac{s}{r}}
$$

em que: $q \alpha=$ é o valor da amplitude estudentizada, cujo valor é encontrado em tabelas, em função do número de tratamentos e do número de grau de liberdade do resíduo, em nível $\alpha$ de probabilidade (em geral 5\%);

$\mathrm{s}=$ é a estimativa do desvio-padrão residual (erro experimental);

$\mathrm{r}=$ número de repetições.

De acordo com o teste, duas médias são estatisticamente diferentes toda vez que o valor absoluto da diferença entre elas for igual ou maior que a DMS. Quando o interesse é comparar todos os pares de médias entre si, neste caso deve-se escolher um procedimento de comparação múltipla tal como o de Tukey (BEZERRA NETO; NUNES; NEGREIROS, 2002).

Para uma variável de custo qualquer, que apresente distribuição normal, foi realizado o teste de Tukey entre duas regiões de maneira a verificar se as médias apresentavam diferenças nessas regiões. Foram feitas comparações entre as regiões Nordeste - Expansão, Nordeste - Tradicional e Tradicional - Expansão. 
Assim, quando o teste de Tukey apresentar p-valor menor que 0,05 são considerados estatisticamente significativos e a diferença pode ocorrer entre todos os grupos das regiões analisadas (Nordeste - Expansão, Nordeste - Tradicional e Tradicional - Expansão) ou apenas entre dois ou um grupo.

Para as variáveis que não tiveram distribuição normal, aplicou-se o teste de Kruskal-Wallis em nível nominal de significância de 5\%, com a finalidade de identificar se ocorrem variações entre as regiões, uma vez que o teste é utilizado na comparação de três ou mais amostras independentes.

A aplicação do teste utiliza os valores numéricos transformados em postos e agrupados num só conjunto de dados, ou seja, se baseia no ranking de cada observação para testar se duas ou mais amostras pertencem à mesma população. A comparação dos grupos é realizada por meio da média dos postos. O teste indica se há diferença entre pelo menos duas delas e a única restrição é que as amostras devem ser independentes (SOKAL; ROHLF, 1995).

"O teste Kruskal-Wallis rejeita a hipótese nula de que todas as populações têm a mesma distribuição quando H é grande" (MOORE, 2005, p. 562). Se o custo médio for igual para as duas regiões, a estatística Kruskal-Wallis terá valor de H baixo e uma distribuição qui-quadrado, com aproximadamente k-1 graus de liberdade, em que k é o número de amostras testadas. Desta forma, quanto maior o valor do Kruskal-Wallis, maior a possibilidade de que haja diferença entre os grupos.

$\mathrm{O}$ teste vem acompanhado do p-valor, que indica a possibilidade, em termos percentuais, que as médias populacionais dos dois grupos têm de serem iguais. P-valor menor que 0,05 são considerados estatisticamente significativos e indica que houve diferença na variável custo de produção analisada em relação às regiões comparadas. Como no teste de Tukey, as diferenças podem ser entre todos os grupos de regiões analisadas (Nordeste - Expansão, Nordeste - Tradicional e Tradicional - Expansão) ou apenas entre dois ou um grupo.

\section{RESULTADOS E DISCUSSÃO}

\subsection{ANÁLISE DESCRITIVA DOS DADOS}

A análise descritiva dos dados possibilitou conhecer o comportamento das regiões produtoras de cana para cada variável associada ao custo de produção. A 
região Centro-Sul tradicional foi a maior produtora de cana-de-açúcar, com média de 381.654.255 toneladas no período compreendido entre as safras 2007/2008 a 2011/2012, e a região com menor produção foi a Nordeste, com média de 62.383 .564 toneladas em igual período (Tabela 1 ).

Verifica-se, pela Tabela 1, que a quantidade produzida de cana-de-açúcar tem variação maior em relação à média, principalmente, nas regiões CentroSul expansão e Centro-Sul tradicional, conforme os coeficientes de variação de 19,94 e 7,54, respectivamente. O valor mínimo produzido pela região Centro-Sul expansão foi de 86.602.339 toneladas, enquanto na região Centro-Sul tradicional foi de 336.683.020 toneladas. A região Nordeste apresenta a produção máxima de 64.099.738 toneladas, valor este abaixo do mínimo produzido nas demais regiões.

Para atingir essa produção de cana no período, a mecanização foi o fator que teve o maior custo, com valores médios de $\mathrm{R} \$ 1.272$, 26/ha na região Centro-Sul expansão, e R\$1.162,63/ha, na região Centro-Sul tradicional (Tabela 1). Melo (2010, p. 57) afirma em seu trabalho que "em termos de custos, é possível verificar que são os custos com mecanização que mais oneram a produção de cana-de-açúcar no Brasil".

Ramos (2007), analisando o futuro da ocupação na agroindústria canavieira do Brasil, enfatiza que a legislação determinou prazo para que as regiões implantassem a mecanização nas áreas com declividade de até $12 \%$. A região Centro-Sul expansão teve legislação posterior à Centro-Sul tradicional (GONÇALVES, 2009), o que pode explicar o custo de mecanização maior nesta região, ou seja, os produtores devem ter investido mais em maquinário, elevando os seus custos, enquanto, na região tradicional, esse investimento já foi realizado em grande parte.

Tabela 1. Estatística descritiva das variáveis utilizadas nas safras 07/08 a 11/12

(Continua)

\begin{tabular}{ccccccc}
\hline Variável & Regióes & Mínimo & Máximo & Média & $\begin{array}{c}\text { Desvio- } \\
\text { padrão }\end{array}$ & $\begin{array}{c}\text { Coeficiente } \\
\text { variação }\end{array}$ \\
\hline $\begin{array}{c}\text { Mecanização } \\
\text { (R\$/ha) }\end{array}$ & EExpansão & 986,00 & 1754,09 & 1272,26 & 322,19 & 25,32 \\
& Nordeste & 623,00 & 905,37 & 745,33 & 124,84 & 16,75 \\
& tradicional & 922,00 & 1534,86 & 1162,63 & 258,51 & 22,23 \\
\hline
\end{tabular}


(conclusão)

\begin{tabular}{ccccccc}
\hline Variável & Regiões & Mínimo & Máximo & Média & $\begin{array}{c}\text { Desvio- } \\
\text { padrão }\end{array}$ & $\begin{array}{c}\text { Coeficiente } \\
\text { variação }\end{array}$ \\
\hline \multirow{2}{*}{ Mão de obra } & Expansão & 203,32 & 619,00 & 402,51 & 201,47 & 50,05 \\
(R\$/ha) & Nordeste & 550,42 & 1185,88 & 823,52 & 228,82 & 27,79 \\
& tradicional & 442,72 & 830,25 & 539,81 & 163,03 & 30,20 \\
\hline \multirow{2}{*}{ Insumos } & Expansão & 424,70 & 677,00 & 571,99 & 108,92 & 19,04 \\
(R\$/ha) & Nordeste & 370,76 & 690,00 & 531,32 & 155,75 & 29,31 \\
& tradicional & 387,93 & 712,00 & 530,52 & 166,25 & 31,34 \\
\hline \multirow{2}{*}{ Arrendamento } & Expansão & 153,00 & 519,63 & 239,27 & 157,85 & 65,97 \\
(R\$/ha) & Nordeste & 56,00 & 163,55 & 109,86 & 50,68 & 46,13 \\
\hline Despesas & tradicional & 84,18 & 905,57 & 281,21 & 350,62 & 124,68 \\
administrativas & Nordeste & 122,82 & 268,00 & 212,82 & 60,02 & 28,20 \\
(R\$/ha) & tradicional & 153,30 & 376,00 & 288,42 & 92,78 & 32,17 \\
\hline Remuneração & Expansão & 199,00 & 358,04 & 255,44 & 73,80 & 28,89 \\
da terra (R\$/ & Nordeste & 172,00 & 342,49 & 233,44 & 70,63 & 30,26 \\
ha) & tradicional & 294,00 & 775,68 & 478,68 & 221,41 & 46,25 \\
\hline Remuneração & Expansão & 125,00 & 413,04 & 219,36 & 117,69 & 53,65 \\
do capital (R\$/ & Nordeste & 98,00 & 359,18 & 192,77 & 107,19 & 55,61 \\
ha) & tradicional & 181,00 & 419,48 & 279,44 & 100,80 & 36,07 \\
\hline \multirow{2}{*}{ Quantidade de } & Expansão & 86.602 .339 & 148.422 .166 & 116.721 .619 & 23.270 .823 & 19,94 \\
& Nordeste & 60.231 .407 & 64.099 .738 & 62.383 .564 & 1.439 .634 & 2,31 \\
\hline & tradicional & 336.683 .020 & 406.839 .256 & 381.654 .255 & 28.758 .048 & 7,54 \\
\hline
\end{tabular}

Fonte: Elaborado pelo autor.

Em relação à região Nordeste, o maior custo médio ( $\mathrm{R} \$ 823,52 / \mathrm{ha})$ é referente à mão de obra e, em seguida, a mecanização (R\$ 745,3/ha) (Tabela 1). Esse fato pode ser explicado por Marques (2009) que afirma em seu trabalho a pouca utilização de máquinas nesta região devido às características dos terrenos e solos. Kohlhepp (2010) também argumenta neste sentido ao analisar a situação da produção de etanol e biodiesel no Brasil, apontando que a baixa fertilidade dos solos e a topografia inadequada para a mecanização contribuem para o aumento dos custos, principalmente, da mão de obra.

Os custos com insumos e mão de obra foram os fatores que mais contribuíram, 
depois da mecanização, no custo de produção da cana na região Centro-Sul tradicional e expansão. Os insumos variaram entre as médias de $\mathrm{R} \$ 530,52 / \mathrm{ha}$ e $\mathrm{R} \$ 571,99 / \mathrm{ha}$. Esses dois custos (insumos e mão de obra) foram os mais relevantes no estudo de Baiyegunhi e Arnold (2011) ao examinarem os fatores que influenciam a produção de cana-de-açúcar em larga escala na África do Sul. Os autores justificam o motivo de esses custos serem os mais elevados, no caso da mão de obra, que é pela natureza da indústria que utiliza a mão de obra intensiva nas lavouras em detrimento da mecanização e, para o caso dos insumos, principalmente, os fertilizantes, esses custos são decorrentes do aumento do preço do óleo no período analisado.

Outro ponto importante apresentado na Tabela 1 diz respeito a terra. Nesse caso, percebe-se que os custos médios da remuneração da terra ( $\mathrm{R} \$ 478,68$ / ha) são maiores na região Centro-Sul tradicional. Esse dado reflete o aumento de 186\% no preço das terras nesta região entre o período de 2007 e 2012, conforme destacado por Xavier (2012). Além disso, para Vieira Júnior et al. (2008), o aumento no preço contribuiu para a expansão da cana-de-açúcar em outras regiões. Isso pode ser notado pelo custo com arrendamento, demonstrando que o preço médio da região Centro-Sul expansão ( $\$$ \$239,27/ha) não apresenta tanta diferença daquele da Centro-Sul tradicional ( $\$ \$ 282,21 / \mathrm{ha}$ ) pelo aumento do arrendamento de terras nos Estados da região Centro-Oeste e de Minas Gerais resultante da instalação de usinas naquelas áreas.

Os custos com as despesas administrativas têm comportamento mais homogêneo entre as três regiôes, pois apresentam valores de desvio-padrão menores, sendo $R \$ 50,11 /$ ha para a região Centro-Sul expansão, $R \$ 60,02 / \mathrm{ha}$, para a região Nordeste, e $\$ \$ 92,78 /$ ha, para a região Centro-Sul tradicional, apontando menor dispersão.

Diante desses dados, com o propósito de inferir se as diferenças são estatisticamente significativas, os resultados dos testes estatísticos são analisados na próxima seção.

\subsection{TESTE DE NORMALIDADE, TESTE KRUSKAL-WALLIS E TESTE DE TUKEY}

Para verificar a normalidade da distribuição dos resíduos das variáveis 
foi utilizado o teste de Anderson-Darling, considerando um nível nominal de significância de 5\% (Tabela 2). O teste indicou que as variáveis mão de obra, insumos, arrendamento e remuneração do capital não apresentaram distribuição normal ( $p$-valor $<0,05)$, enquanto as demais tiveram distribuição normal ( $p$-valor $>0,05)$.

Tabela 2. Teste Anderson-Darling dos resíduos para as variáveis de custo de produção

\begin{tabular}{lcc}
\hline \multicolumn{1}{c}{ Variável } & Anderson-Darling & $p$-valor \\
\hline Mecanização (R\$/ha) & 0,3162 & 0,5070 \\
Mão de obra (R\$/ha) & 0,8494 & 0,0216 \\
Insumos (R\$/ha) & 0,7882 & 0,0313 \\
Arrendamento (R\$/ha) & 1,4390 & 0,0006 \\
Despesas administrativas (R\$/ha) & 0,3882 & 0,3408 \\
Remuneração da terra (R\$/ha) & 0,3711 & 0,3758 \\
Remuneração do capital (R\$/ha) & 0,8791 & 0,0181 \\
\hline
\end{tabular}

Fonte: Elaborado pelo autor.

Para verificar se houve diferença das variáveis com relação às regiões, foi realizado o teste de Kruskal-Wallis para as variáveis que não apresentaram distribuição normal (Tabela 3).

Tabela 3. Teste Kruskal-Wallis para variáveis que não apresentaram distribuição normal nos custos de produção da cana-de-açúcar nas regiões produtoras brasileiras

\begin{tabular}{lcccc}
\hline \multicolumn{1}{c}{ Região } & Mão de obra & Insumos & Arrendamento & Remuneração do capital \\
\hline Expansão - Nordeste & Sim & Não & Não & Não \\
Expansão - tradicional & Não & Não & Não & Não \\
Nordeste - tradicional & Não & Não & Não & Não \\
\hline p-valor* & $\mathbf{0 , 0 4 8 4}$ & 0,8863 & 0,1198 & 0,4429 \\
\hline
\end{tabular}

* $P$-valor menor que 0,05 são considerados estatisticamente significativos e indica que houve diferença na variável custo de produção analisada em relação às regiões.

Fonte: Elaborado pelo autor. 
Dentre as variáveis que tiveram o teste Kruskal-Wallis realizado, apenas a variável mão de obra apresentou diferença significativa $(p$-valor $=0,0484)$, contudo foi verificada a diferença somente entre as regiões Centro-Sul expansão e Nordeste (Tabela 3). Para Marques (2009), na região Nordeste, a pequena escala de produção e a intensiva utilização da mão de obra nas etapas de plantio e colheita, podem ser apontadas como os principais gargalos na produção de cana-de-açúcar. Assim, a mão de obra representa um custo bastante elevado nessa região, o que pode determinar a diferença. Além disso, Reetz et al. (2013) notaram que a tendência de alta nos custos de produção da região Nordeste ocorreu por diversos fatores, entre eles, os gastos com mão de obra.

Com relação às variáveis com distribuição normal, foi realizado o teste de Tukey (Tabela 4) e as variáveis custo de mecanização e remuneração da terra apresentaram p-valor menor que 5\%, resultando numa variação estatisticamente significativa. No entanto, a variável despesas administrativas não se apresentou estatisticamente significativa.

Tabela 4. Teste de Tukey para variáveis com distribuição normal nos custos de produção da cana-de-açúcar nas regiões produtoras brasileiras

\begin{tabular}{lccc}
\hline \multicolumn{1}{c}{ Região } & Mecanização & $\begin{array}{c}\text { Despesas } \\
\text { administrativas }\end{array}$ & $\begin{array}{c}\text { Remuneração da } \\
\text { terra }\end{array}$ \\
\hline Nordeste - Expansão & $0,02^{* *}$ & $0,82^{* *}$ & $0,96^{* *}$ \\
Tradicional - Expansão & $0,77^{* *}$ & $0,09^{* *}$ & $0,06 * *$ \\
Tradicional - Nordeste & $0,06^{* *}$ & $0,24^{* *}$ & $0,04^{* *}$ \\
\hline P-valor* & $\mathbf{0 , 0 1}$ & 0,09 & $\mathbf{0 , 0 3}$ \\
\hline
\end{tabular}

Nível de significância: 0,05 ; ${ }^{*} P$-valor menor que 0,05 são considerados estatisticamente significativos e indica que houve diferença na variável custo de produção analisada em relação às regiões; *** Valores abaixo de 0,05 indica que houve diferenças nas comparações das regióes duas a duas para determinada variável.

Fonte: Elaborado pelo autor.

A variável custo de mecanização apresentou diferença somente quando comparadas às regiões Nordeste e Centro-Sul expansão (Tabela 4). Isso pode ser reflexo do aumento da tecnologia nos equipamentos de colheita/plantio nas lavouras 
da região Centro-Sul expansão em oposição a grande utilização de mão de obra no Nordeste.

A remuneração da terra apresentou diferença entre as regiões Centro-Sul tradicional e Nordeste. Uma das causas pode ser o valor elevado das terras no Estado de São Paulo, o que leva os investidores a implantar novas usinas em locais que tenham um custo de aquisição da terra mais favorável (SZMRECSÁNYI et al., 2008). Isto pode ser verificado, conforme Tabela 1 , pela média da remuneração da terra que é mais elevado na região tradicional ( $\mathrm{R} \$ 478,68 / \mathrm{ha}$ ) quando comparada com as demais regiões. Marques (2009) argumenta que a região Centro-Sul expansão teve maior rentabilidade que a tradicional por diversos fatores, entre eles, o menor custo da terra.

Neste sentido Torquato, Martins e Ramos (2009) concluíram, de modo geral, ao utilizarem o arrendamento como uma variável de mensuração da eficiência, que as regionais que apresentavam menor custo de arrendamento também eram mais eficientes.

\section{CONSIDERAÇÕES FINAIS}

A cultura da cana-de-açúcar representa importante segmento do agronegócio brasileiro. E a pesquisa sobre eficiência é relevante a fim de contribuir para o aumento da produtividade e elucidar os possíveis fatores determinantes da ineficiência.

Nesta pesquisa, foi realizado o detalhamento dos custos de produção nas três regiões e o maior custo médio relacionado à produção da cana-de-açúcar foi o da mecanização, estando em conformidade com Melo (2010); no entanto, na região Nordeste, o mais relevante é o da mão de obra, que é explicado em parte, pelas justificativas apresentadas por Marques (2009). Estes dois custos apresentaram diferença estatística significante entre as regiões Centro-Sul expansão e Nordeste.

Por fim, a outra variável que apresentou diferença estatisticamente significante foi o arrendamento de terras, mas apenas entre as regiões Tradicional e Nordeste. Sugere-se para futuras pesquisas que seja avaliada a eficiência técnica e de escala entre as regiões. 


\section{REFERÊNCIAS}

ALVES, C. L. B. Liberalização Comercial: aspectos teóricos e estratégias recomendadas. Revista de Economia \& Relações Internacionais, São Paulo, v. 7, n. 14, p. 5 - 19, jan., 2009.

ARANGO, H. G. Bioestatística teórica e computacional. Rio de Janeiro: Guanabara Koogan, 2001.

BAIYEGUNHI, L. J. S.; ARNOLD, C. A. Economics of sugarcane production on large scale farms in the Eshowe/Entumeni areas of KwaZulu-Natal, South Africa. African Journal of Agricultural Research, Lagos, v. 6, n. 21, p. 4960-4967, oct. 2011.

BEZERRA NETO, F.; NUNES, G. H. S.; NEGREIROS, M. Z. de. Avaliação de procedimentos de comparações múltiplas em trabalhos publicados na revista Horticultura Brasileira de 1983 a 2000. Horticultura Brasileira, Brasília, v. 20, n. 1, p. 05-09, mar., 2002.

BRASIL. Ministério da Agricultura, Pecuária e Abastecimento. Intercâmbio comercial do agronegócio: principais mercados de destino. Ministério da Agricultura, Pecuária e Abastecimento. Secretaria de Relações Internacionais do Agronegócio. Brasília, DF, 2012. Disponível em: <www.agricultura.gov.br> . Acesso em 23 abril 2014.

BRUNOZI JÚNIOR, A. C.; ABRANTES, L. A.; GOMES, A. P.; GONÇALVES, R. M. L. Eficiência produtiva e análise econômica e financeira de usinas de cana-de-açúcar do Estado de São Paulo. Revista Ambiente Contábil, Natal, v. 4, n. 2, p. 74-92, jul./ dez., 2012.

CARVALHO, F. M.; FIÚZA, M. A.; LOPES, M. A. Determinação de custos como ação de competitividade: estudo de um caso na avicultura de corte. Revista Ciência e Agrotecnologia, Lavras, v. 32, n. 3, p. 908-913, maio/jun. 2008.

CARVALHO, G. R.; OLIVEIRA, C. de. O setor sucroalcooleiro em perspectiva. Campinas, SP: Embrapa, 2006. Disponível em: < http://www.cnpm.embrapa.br/ publica/download/cit10_sugaralcool.pdf > . Acesso em: 23 maio 2014.

CHADDAD, F. R.. UNICA: Challenges to deliver sustainability in the brazilian 
sugarcane industry. International Food and Agribusiness Management Review, Washington, v. 13, n. 4, p. 173-192, 2010.

DYSON, R. G.; ALLEN, R.; CAMANHO, A. S.; PODINOVSKI, V. V.; SARRICO, C. S.; SHALE, E. A. Pitfalls and protocols in DEA. European Journal of Operational Research, Amsterdam, v. 132, n. 2, p. 245-259, 2001.

ESTATCAMP. Action ${ }^{\circledR}$ versão 2.5.197.344. [2014] Disponível em: < http://www. portalaction.com.br/ > . Acesso em: 20 maio 2014.

FREITAS, R. E.; MENDONÇA, M. A. A. de. O mercado internacional sucroalcooleiro para o Brasil. Revista de política agrícola, Brasília, ano 17, n. 3, p. 44-50, jul./set. 2008.

GONÇALVES, D. B. Considerações sobre a expansão recente da lavoura canavieira no Brasil. Informações Econômicas, São Paulo, v. 39, n. 10, p. 70-82, out. 2009.

KENNEDY, P. L.; HARRISON, R. W.; PIEDRA, M. A. Analyzing agribusiness competitiveness: The case of the United States sugar industry. International Food and Agribusiness Management Review, Washington, v. 1, n. 2, p. 245-257, 1998.

KOHLHEPP, G. Análise da situação da produção de etanol e biodiesel no Brasil. Estudos Avançados, São Paulo, v. 24, n. 68, p. 223-253, 2010.

MARQUES, P. V. (Coord.). Custos de produção agrícola e industrial de açúcar e álcool no Brasil na safra 2007/2008. Piracicaba: ESALQ/USP, 2009. Relatório apresentado a Confederação da Agricultura e Pecuária do Brasil - CNA.

MARTINS, A. P.; GOMES, M. F. M.; ROSADO, P. L.; FERREIRA NETO, J. Competitividade do sistema produtivo de cana-de-açúcar em Minas Gerais: abordagem da matriz de análise política. Revista de economia e agronegócio, Viçosa, v. 5, n.1, p. 73-100, 2007.

MELO, C. O. de. Eficiência econômica da produção de cana-de-açúcar de produtores independentes do Estado do Paraná. 2010. 92f. Tese (Doutorado em Agronomia) - Universidade Estadual Paulista, Botucatu, 2010. 
MOORE, D. S. Estatística básica e sua prática. 3. ed., Rio de Janeiro: LTC, 2005.

NEVES, M. F.; TROMBIN, V. G.; CONSOLI, M. A. Measurement of sugar cane chain in Brazil. International Food and Agribusiness Management Review, Washington, v. 13, n. 3, p. 37-54, 2010.

NEVES, M. F.; TROMBIN, V. G.; CONSOLI, M. A.; JULCA-BRICENO; B. M.; NOGUEIRA, A. J. G. Análisis del sector sucroenergético brasileño bajo um enfoque de planificación estratégica. Agroalimentaria, Caracas, v. 17, n. 32, p. 29-45, ene.jun. 2011.

NICOLELI, M.; MOLLER, H. D. Análise da competitividade dos custos do café orgânico sombreado irrigado. Custos e @gronegócio on line, Recife, v. 2, n. 1, p. 29-44, fev. 2006. Disponível em: <http://www.custoseagronegocioonline.com. br/numero1v2/Custos\%20do\%20cafe\%20organico.pdf>. Acesso em: 01 mar. 2014.

NUNEZ, H. M. How relevant has been the learning-by-doing for Brazilian sugarcane ethanol production? Centro de Investigação e Docencia Económicas, Alvaro Obregón, n. 552, 2013. Disponível em: < http://www.cide.edu/> . Acesso em: 26 maio 2014.

OLIVEIRA, M. D. M.; NACHILUK, K. Custo de produção de cana-de-açúcar nos diferentes sistemas de produção nas regióes do Estado de São Paulo. Informaçóes Econômicas, São Paulo, v. 41, n. 1, p. 5-33, jan. 2011.

RAMOS, P. O futuro da ocupação na agroindústria canavieira do Brasil: uma discussão dos trabalhos disponíveis e um exercício de estimação. Informações Econômicas, São Paulo, v. 37, n. 11, p. 69-75, nov., 2007.

REETZ, E. R.; KIST, B. B.; SANTOS, C. E. dos; CARVALHO, C. de; POLL, H. Anuário brasileiro da cana-de-açúcar 2013. Santa Cruz do Sul: Ed. Gazeta Santa Cruz, 2013.

SILVA, C. B. Inovação na indústria sucroalcooleira paulista: os determinantes da adoção das tecnologias de agricultura de precisão. 2009. 89f. Tese (Doutorado em Ciências) - Universidade de São Paulo, Piracicaba, 2009. 
SOKALL, R. R.; ROHLF, F. J. Biometry: the principles and practice of statistics in biological research. $3^{\text {rd }}$ ed. New York: W. H. Freeman, 1995.

SZMRECSÁNYI, T.; RAMOS, P.; RAMOS FILHO; L. O.; VEIGA FILHO, A. A. Dimensões, riscos e desafios da atual expansão canavieira. Brasília, DF: Embrapa Informação Tecnológica, 2008.

TORQUATO, S. A.; MARTINS, R.; RAMOS, S. F. Cana-de-açúcar no Estado de São Paulo: eficiência econômica das regionais novas e tradicionais de produção. Informações Econômicas, São Paulo, v. 39, n. 5, p. 92-99, 2009.

UNIÃO DA INDÚSTRIA DE CANA-DE-AÇÚCAR. Como avançar com a bioeletricidade. Disponível em: < http://www2.camara.leg.br/atividade-legislativa/ comissoes/comissoes-permanentes/cme/audiencias-publicas/01-04-2014-seminariofarina >. Acesso em: 03 out. 2014.

VIANA, K. R. O.; PEREZ, R. Survey of sugarcane industry in Minas Gerais, Brazil: Focus on sustainability. Biomass and Bioenergy, Oxford, n. 58, p. 149-157, 2013.

VIEIRA JÚNIOR, P. A.; PINTO VIEIRA, A. C.; BUAINAN, A. M.; LIMA, F. de; SILVEIRA, J. M. F. J. da. Produção brasileira de cana de açúcar e deslocamento da fronteira agrícola no Estado de Mato Grosso. Informações Econômicas, São Paulo, v. 38, n. 4, p. 58-77, abr. 2008.

XAVIER, C. E. O. The evolution of production cost in Brazil's cane industry. F. O. Licht's International Sugar and Sweetener Repor, London, v. 144, n. 11, p. 204207, 2012.

Recebido em: 01 de maio de 2016 Aceito em: 01 de setembro de 2016 